\title{
Study of Anthropometric and Morphological Observations of External Ear in Western Maharashtrian Population
}

\author{
J. M. Durgawale ${ }^{1}$, S. S. Jadhav ${ }^{2}$ \\ ${ }^{1}$ Assistant Professor, Department of Anatomy, RCSM Govt Medical College Kolhapur \\ ${ }^{2}$ Professor and Head, RCSM Govt Medical College Kolhapur
}

\begin{abstract}
This study aimed at determining the normal anthropometric measurements and morphological observations of external ear in males and females and their comparison on either sides and in either sex. The study was carried out on 220 randomly selected students of Kolhapur district Maharashtra with no evidence of congenital ear anomalies or previous ear surgeries. The study cohort consisted of 110 females and 110 males aged 18-25years. Vernier Calipers were used to measure the bilateral sizes of external ear. Parameters were total ear length, ear width, lobular length and lobular width, conchal length and conchal width. It was observed that all parameters were significantly larger on right side in both males and females which was statistically significant. All measurements were found higher in males than in females on both sides, total ear length and ear width were found to be significantly greater. These findings suggest that the normal anthropometric study will have implications in the cosmetic surgeries, correction of malformations, designing of head phones, ear phones and hearing aids.
\end{abstract}

Keywords: anthropometric, measurements, Vernier caliper

\section{Introduction}

The external ear consists of auricle or pinna and external acoustic meatus. The auricle is made up of elastic cartilage lined by skin on both sides. The lower part of the auricle is made up of connective tissue covered by skin which is called as lobule. A vast knowledge of normal ear dimensions will be of much use for the plastic surgeons rectifying the possible ear pinna defects. The forensic specialist needs the ear pinna dimensions for identifying a person, whereas the manufacturer needs for making ear prosthesis. The dimensions vary in different ethnic groups, which necessitate them to base their observations on the data specific to the ethnic group. The measurement of human individual is known as Anthropometry (anthrops-human and metron measure). Anthropometry refers to the measurements of living human body dimensions for the purpose of understanding human physical variation as it plays an important role in plastic surgery, prosthetics and so on for data collection. ${ }^{1}$ Anthropometric measurements have uses in epidemiology and medical anthropology, in helping to determine the relationship between various body measurements such as the height, weight, percentage, body fat and medical outcomes. Anthropometry involves the systematic measurement of the physical properties of the human body, primarily dimensional descriptors of body size and shape.

This study aimed at determining the normal anthropometric measurements and morphological observations of external ear in males and females and their comparison on either sides and in either sex which create awareness for the knowledge of people in determining the relationship of external ear measurements to the variations of the mean values among individuals..

\section{Materials and Method}

The measurements of external ears of both right and left ears among 220 randomly selected individuals were taken. It consisted of 110 females and 110 males. The measurements were carried out for each subject twice to get accuracy and mean of two measurements was considered for each dimension. Also Ear Index (ear width/ ear height x 100) and Lobule Index (lobule width/lobule height $x$ 100) were calculated for each subject ${ }^{2}$. The ear morphological observations considered were the ear lobule attachment was noted as attached or free. Also presence or absence of Darwin tubercle and flat or rolled helix type were observed. After completion by the subjects, the values were noted and interpreted in accordance with the norms. It helps in determining the values of external ears and in identifying to which extent individuals differ in their values. The purpose of study was explained to the subjects; their willingness and cooperation were considered.

All the measurements were taken by the single investigator using vernier calipers capable of measuring to the nearest $0.1 \mathrm{~mm}$. Comparison of the measurements according to gender were performed using an independent samples t-test. Comparison of measurements taken from the right and left ears of a given sex was performed using paired samples ttest. 


\section{International Journal of Science and Research (IJSR) \\ ISSN (Online): 2319-7064}

Index Copernicus Value (2015): 78.96 | Impact Factor (2015): 6.391

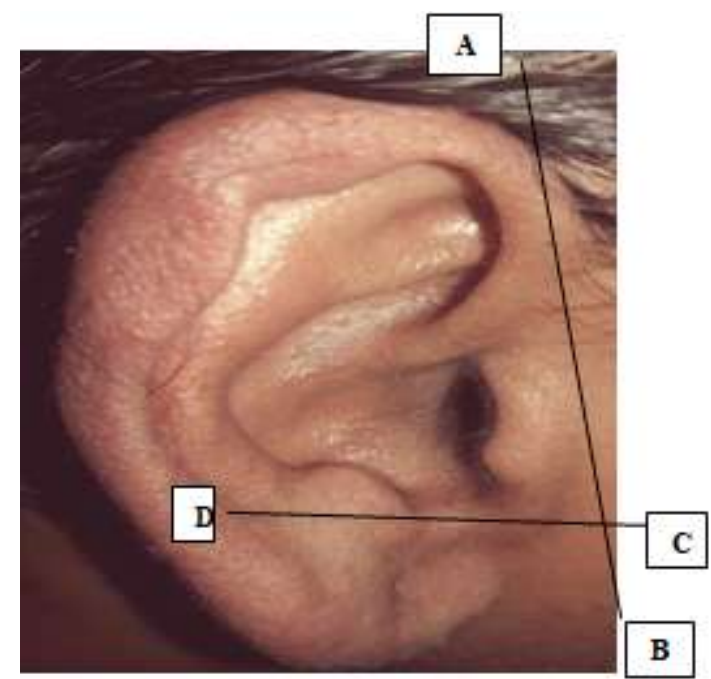

Figure 1: Showing length (A-B) and width (C-D) of external ear lobe

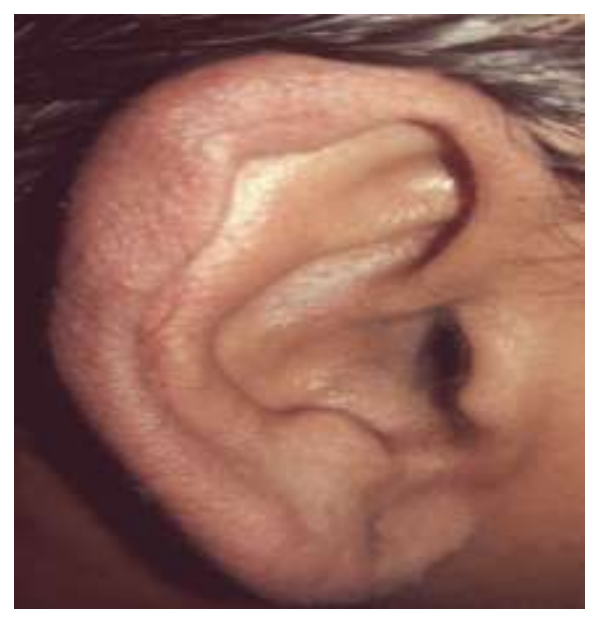

Figure 2: showing length (E-F) and width $(\mathrm{G}-\mathrm{H})$ of ear concha and length (K-L) and width (I-J) of ear lobe.

\section{Results and Discussion}

The study was carried out on 220 randomly selected students of Kolhapur district Maharashtra with no evidence of congenital ear anomalies or previous ear surgeries. The study cohort consisted of 110 females and 110 males aged 1825years. The The auricle reaches its mature height at 13 years in male and at 12 years in females. ${ }^{3}$ Anthropometric studies had been carried out on the external ear of children with different conditions such as cleft lip/palate, ${ }^{4}$ Down's syndrome ${ }^{5}$ Existence of sexual dimorphism in external ear dimensions were documented. ${ }^{6}$ It was shown that sexual dimorphism exists in auricular linear dimensions between males and females with higher values in males. ${ }^{7}$ This is similar to the findings of Bozkir et al. $(2006)^{8}$ who observed significant difference in ear height between Turkish and Japanese populations. In the same study, it was also shown that the total auricular length and width were longer in males within the Turkish population. It was therefore concluded that all auricular dimensions were significantly larger in males than in females. The morphological observations and dimensions of external ear vary in different human ethnic races which can be utilized in forensics for personal identification of living or deceased. ${ }^{9}$
Morphological observed parameteres included presence or absence of Darwin tubercle, Helix type- flat/rolled and ear lobe attachment to cheek.

The present study found $80 \%$ individuals with presence of Darwin tubercle and 20\% with absence of it. ( Table 2 )

Rolled helix $99.54 \%$ was observed to have much common occurrence as compared to the flat helix $0.45 \%$.(Table 2)

The attached ear lobe was observed to be present in $29.09 \%$ subjects whereas it was free in $70.90 \%$ subjects. (Table 2)

Among the parameters of measurements ear length, ear width, ear lobe length, ear lobe width, concha length, concha width, ear index and lobe index were analysed and it was found that measurements and comparison of results according to genders who participated in the study are shown in table 1 where all the dimensions were higher in males as compared to the female subjects and showed that the right ear indices were significantly larger than the left ear indices in both male and female subjects

Table 1: Statistical analysis of measurements

\begin{tabular}{|c|c|c|c|c|c|c|}
\hline \multirow{2}{*}{ Parameters } & \multicolumn{3}{|c|}{ Male (110 ) } & \multicolumn{3}{c|}{ Female (110 ) } \\
\cline { 2 - 7 } & $\begin{array}{c}\mathrm{R} \\
\text { Mean }\end{array}$ & $\begin{array}{c}\mathrm{L} \\
\text { Mean }\end{array}$ & $\mathrm{R}+\mathrm{L}$ & $\begin{array}{c}\mathrm{R} \\
\text { Mean }\end{array}$ & $\begin{array}{c}\mathrm{L} \\
\text { Mean }\end{array}$ & $\mathrm{R}+\mathrm{L}$ \\
\hline Ear length & 6.05 & 5.90 & 5.97 & 5.72 & 5.60 & 5.66 \\
\hline Ear width & 3.19 & 3.28 & 3.23 & 3.01 & 2.91 & 2.96 \\
\hline Ear lobe length & 1.81 & 1.72 & 1.76 & 1.61 & 1.62 & 1.61 \\
\hline Ear lobe width & 1.94 & 1.97 & 1.95 & 1.88 & 1.95 & 1.91 \\
\hline Concha length & 2.58 & 2.56 & 2.57 & 2.37 & 2.31 & 2.34 \\
\hline Concha width & 1.63 & 1.73 & 1.68 & 1.61 & 1.57 & 1.59 \\
\hline Ear index & 52.72 & 55.59 & 54.15 & 52.62 & 51.96 & 52.29 \\
\hline Lobule index & 107.18 & 114.53 & 110.85 & 116.77 & 120.37 & 118.57 \\
\hline
\end{tabular}

Table 2: Morphological observation parameters

\begin{tabular}{|c|c|c|c|c|c|}
\hline Parameters & Observations & Male & Female & Total & $\%$ \\
\hline \multirow{2}{*}{$\begin{array}{c}\text { Darwin } \\
\text { tubercle }\end{array}$} & Present & 89 & 87 & 176 & 80 \\
\cline { 2 - 6 } Helix type & Absent & 21 & 23 & 44 & 20 \\
\cline { 2 - 6 } & Rolled & 109 & 110 & 219 & 99.54 \\
\hline \multirow{2}{*}{$\begin{array}{c}\text { Ear lobe } \\
\text { type }\end{array}$} & Flat & 01 & 00 & 01 & 0.45 \\
\cline { 2 - 6 } & Free & 29 & 35 & 64 & 29.09 \\
\hline
\end{tabular}

\section{Conclusion}

This study provides the mean values of different morphometric measurements of right and left ears in the students of Kolhapur district. As a result, the present study has established the existence of sexual dimorphism in external ear dimensions and also the differences between the auricular indices of both sides. The result shows that there is significant correlation between the ear variables. If all measurements and morphological observations taken into consideration gives information on age and sex which plays a valuable role in forensic investigation. Now the ear lobes are also used in otomorphology for identification. Therefore data obtained in the present study would serve some purposes in ear morphology and anthropometric consideration.

\section{Volume 6 Issue 10, October 2017 www.ijsr.net}


Thus the use of ear dimensions in anthropometry for characterization of the differences in sex was highlighted in the present study. Knowledge about the normal auricular dimensions is important in the diagnosis of congenital malformations, syndromes and acquired deformities thus the study has implications in the cosmetic surgeries, correction of malformations, designing of head phones, ear phones and hearing aids. In future study will be continued to relate the results of our present study to the height of an individual and various facial/cranial anthropometric parameters in correlation with the bite mark analysis for forensic investigations.

\section{References}

[1] Deopa D. et. al (2013). Anthropometric measurements of external ear of medical students in Uttarakhand region. Jour. Of the anat. Society of India 62:79-83.

[2] Taura M. G. et al (2013). External ear anthropometry among Hausas of Nigeria; the search of sexual dimorphismand correlations. World Journal of Medicine and Medical Science Research.1 (5):091-095.

[3] Sforza C ,Grandi G, Binelli M, Tommasi DG age and sex related changes in the normal human ear. Forensic Sci Int 2009;187(1):110.e1-110.e7

[4] Nathan N, Latham K, Cooper J, Perlyn C, Gozlan I, Thaller SR (2008). Anthropometry of the external ear in children with cleft lip and palate in comparison to agematched controls. J. Craniofac. Surg., 19: 1391-1395.

[5] Sforza C, Dellavia C, Tartaglia GM, Ferrario VF (2005). Morphometry of the ear in Down's syndrome subjects: A three-dimensional computerized assessment. Int. J. Oral Maxillofa. Surg., 34: 480-486.

[6] Ito I et. al (2001). A morphological study of age changes in adult human auricular cartilage with special emphasis on elastic fibres. Laryngoscope 111:881-6.

[7] Brucker MJ, Patel J, Sullivan PK (2003). A morphometric study of the external ear: Age and sex related differences. Plast. Reconstr. Surg., 112: 647-652.

[8] Bozkir MG, Karakas P, Yavuz M, Dere F (2006). Morphometry of the external ear in our adult population, Aesth. Plast. Surg., 30: 81-85.

[9] B. senthil, G. Panneer Selvi (2016). Morphometry of ear pinna in sex determination, Int J Anat Res 2016, vol 4 (2):2480-84.

\section{Author Profile}

Dr J. M. Durgawale is Assistant Professor, Department of Anatomy, RCSM Govt Medical College Kolhapur

Dr. S. S. Jadhav is Professor and Head, RCSM Govt Medical College Kolhapur

Volume 6 Issue 10, October 2017 www.ijsr.net 